Hypotheses

\title{
Health Workers' Emotional Intelligence Development: An Examination of the Potential Roles of Tenure, Education and Training
}

\author{
${ }^{1}$ Nestor Asiamah, ${ }^{2}$ Henry Kofi Mensah and ${ }^{3}$ Eric Fosu Oteng-Abayie \\ ${ }^{1}$ Africa Centre for Epidemiology, Accra, Ghana \\ ${ }^{2,3}$ Kwame Nkrumah University of Science and Technology, Kumasi Ghana
}

\author{
Article history \\ Received: 08-07-2016 \\ Revised: $10-10-2016$ \\ Accepted: 15-10-2016 \\ Corresponding Author: \\ Nestor Asiamah \\ Africa Centre for \\ Epidemiology, Accra, Ghana \\ Email: nestor.asiamah@yahoo.com
}

\begin{abstract}
Health workers' emotional intelligence improvement has been highly recommended by researchers for enhancing healthcare. In this study, the researchers attempted to empirically test the potential roles of tenure, education and training as methods for developing the emotional intelligence of health workers. A self-reported questionnaire was employed to collect data from 1,049 randomly selected health workers from all healthcare institutions in Accra North. Confirmatory Factor Analysis was used to present results. The resulting model was of a good fit $\left(\chi^{2}=2.382 ; \mathrm{p}=\right.$ $0.123)$. Moreover, tenure, education and training each significantly predicts health workers' emotional intelligence at 5\% significance level. Whiles training best predicts emotional intelligence and can be prioritized as a means of improving it, education and tenure have roles to play as alternative methods for developing health workers' emotional intelligence, especially when gender equity in terms of education and access to training is ensured. This study therefore recommends the use of in-service training, education and tenure elongation by management of healthcare institutions to enhance health workers' emotional intelligence, with in-service training prioritized among these three methods.
\end{abstract}

Keywords: Emotional Intelligence, Healthcare, Training, Education, Tenure, Gender, Health Workers

\section{Introduction}

The last five decades have been characterized by academic debate on Emotional Intelligence (EI) on a global scale. Primarily this debate has been geared towards the explanation and justification of EI as a cognitive ability that facilitates everyday behavior. Various models, such as the theories of Goleman (1995; Bar-On, 1997), have also been developed to justifiably conceptualize EI as a competence better than Intelligent Quotient and Social Intelligence. Thus proponents conceptualize EI as a skill that better represents humans' cognitive ability, though criticisms have been hatched against the progress of this theory. A typical criticism is the argument that EI is not a form of intelligence but is merely a moral quality (Petrides and Furnham, 2000). Theories and conceptions on EI have also been called mere pop psychology (Locke, 2005), whereas critics even strongly contend that EI lacks predictive validity (Landy, 2005). Interestingly, critics seem to be swimming against a formidable tide of EI debate-their criticisms have failed to terminate the progress of EI research. Before shedding light on this assertion, there is the need to first understand what EI is.

According to Freshman and Rubino (2002), the Consortium for Research on Emotional Intelligence in Organizations described EI as “...social and emotional abilities that previous research has shown to be linked to successful performance in the workplace". EI is also defined as "... the ability to accurately perceive emotions, to access and generate emotions so as to assist thought, to understand emotions and emotional knowledge and to reflectively regulate emotions so as to promote emotional and intellectual growth" (Mayer et al., 2004). In other words, emotional intelligence is a cognitive ability that enables an individual to perceive and understand emotions of self as well as those of others and be able to regulate these emotions in a manner that engenders positive results for self and others. For instance, acceptable behavior in society is facilitated by EI (Brackett et al., 2004). 
In everyday life, humans interact with one another. In fact, we cannot avoid communications between us and relatives, friends, bosses and work mates. Theories of EI basically argue that EI is a cognitive skill that enables humans to succeed in these relationships. More interestingly, a plethora of studies (e.g., Brackett et al., 2004; Danquah and Wireko, 2014; Opuni et al., 2014; Kaur et al., 2015; Tyczkowski et al., 2015; Ozer et al., 2016) have confirmed that EI positively impacts everyday behavior and business performance indicators (e.g., job performance, service quality, customer satisfaction, etc.), though some studies have not confirmed these effects (Farooq and Ur Rehman, 2011).

The body of studies confirming the effect of EI on everyday behavior and some performance indicators is growing by the day in view of evidences recently provided by some researchers (e.g. Ozer et al., 2016; Bowen et al., 2016). Particularly in the healthcare sector, a confirmation of the positive effect of EI on healthcare quality delivery and the performance of health workers has been consistent. Researchers (e.g., Freshman and Rubino, 2002; Kalyoncu et al., 2012; Nwankwo et al., 2013; Ozer et al., 2016) may therefore have a good reason to suggest the need for health workers to be equipped with EI to enhance healthcare quality and performance. In fact, the number of researchers who have been emphatic about similar suggestions in the literature is significantly large. This notwithstanding, several concerns relating to EI and its research have not been addressed in the literature.

While the researchers admit that healthcare quality improvement is a global agenda, they equally admit the need for research on EI to be rigorous and culturally balanced. More importantly, EI research is expected to accompany bolder blueprints for implementing findings. Sadly, confirmed effects of EI on variables such as healthcare performance and quality have not been accompanied with recommendations that can sufficiently guide healthcare policy towards enhancing the EI of health workers. This appalling situation is attributable to the failure of researchers to examine the effect of relevant demographic and background variables on EI.

To explain, proponents of EI and researchers (e.g., Freshman and Rubino, 2002; Kernbach and Schutte, 2005) have recommended on-the-job training (OJT) as the ideal means to increase the EI level of health workers. As acknowledged by Schutte et al. (2013) however, the literature provides little empirical evidence on the effect of on-the-job training on EI enhancement. Moreover education and tenure are background variables that may interact with each other and on-the-job training as implied by the Tenure and Work Experience Effects (TWEE) Theory of Burdett and Coles (2010), which is later discussed in this study. The researchers are of the view that empirical evidences on the extent to which EI is affected by training, education and tenure can be a better way to articulate suggestions for future research and enhancing the EI of health workers through human resource policy development and implementation.
For instance, if tenure makes a significant positive effect on EI development, healthcare institutions and governments would be certain of the effectiveness of providing career development opportunities to healthcare workers as a way of boosting their EI. Similarly, if training makes a significant effect on EI, stakeholders may have to use training and development programs to enhance health workers' EI. The TWEE theory of Burdett and Coles (2010) and Goleman's (1995) EI theory imply that tenure, education and training can be correlated. If so, there may be instances when one of them must be prioritized as a method for developing health workers' EI when this correlation and its influence on EI are simultaneously considered. Moreover depending on the nature of this correlation and its influence on EI, applying tenure (i.e., career development programs), education and training together as means of developing health workers' EI may yield maximum impact.

In addition, some jurisdictions have not yet embraced emotional intelligence research (Farooq and Ur Rehman, 2011), possibly owing to the concept's relative immaturity in the literature. As a consequence, empirical evidences on the relevance of EI to healthcare cannot be applied to some jurisdictions such as Ghana and, possibly, its West African neighbors. Though a handful of studies (e.g., Danquah and Wireko, 2014; Opuni et al., 2014) have been carried out in Ghana on EI, none of them drew data and evidences from the healthcare sector. Even if there are any EI studies conducted in Ghana in the healthcare sector, they are not identifiable; and, in this situation, they are of little influence on academic debate and policy development and implementation. This study is carried out to set the stage for gearing EI research towards the improvement of healthcare performance in Ghana and other developing countries. It thus attempts to make better practical recommendations for policy development and implementation by examining the effects of education, tenure and On-theJob Training (OJT) on health workers' EI.

\section{Literature Review}

Over the years, three theories of emotional intelligence have dominated the academic literature and informed the course of research. One of the earliest among them is Bar-On's (1997) emotional intelligence theory, which conceptualizes EI as a set of interrelated emotional and social competencies that determine how effectively people understand and express themselves, understand others and relate with them and cope with the demands of daily life. This theory postulates that EI is a cognitive skill or a form of intelligence that facilitates success in humans' daily relationship development. The same understanding is provided by Salovey and Mayer (1989), who were the first to formally mention EI in the literature (Freshman and Rubino, 2002). 
The theory of Salovey and Mayer (1989) explains EI as a competence of four skills: (i) The accurate perception, appraisal and expression of people's motions; (ii) generating feelings on demand when they can facilitate understanding of yourself or persons; (iii) understanding emotions and the knowledge that can be derived from them; and (iv) regulation and control of emotion to promote emotional and intellectual growth. Knowledge of these four skills influence modern research on EI and constituted the foundation of the research work of Goleman (1995), who popularized the concept of EI among academics (Freshman and Rubino, 2002; Bowen et al., 2016).

Goleman (1995) is one of the several researchers who were attracted to the earlier work of Bar-On (1997) and Salovey and Mayer (1989), resulting in his reconceptualization of EI as a cognitive ability of five dimensions. The popularity of EI is ascribed to his fivedimension EI concept for a couple of reasons. Firstly, Goleman's (1995) concept is represented by a framework that more comprehensively explains the four EI competences earlier defined by Salovey and Mayer (1989). Secondly, his work decomposes EI into five empirically validated dimensions and serves as the embodiment of the mixed EI model, the most holistic conceptualization of EI (Freshman and Rubino, 2002).

The mixed model is one of the three EI frameworks, with the other two being the ability model and trait model (Mayer, 2008; Opuni et al., 2014). The ability model considers emotions of self and others as useful sources of information that help one to make sense of the social environment and navigate it (Goleman, 1998). It asserts that individuals are different with respect to their ability to process emotion-driven information and in their capacity to relate emotional processing to a wider level of cognition. This model is entirely explained by the four EI competences of Salovey and Mayer (1989), which have been identified earlier in this study. Thus the ability model has three goals: Perceiving emotions; understanding emotions; and managing emotions.

The second model, the trait model, refers to an individual's self-perceptions of their emotional abilities (Freshman and Rubino, 2002; Mayer, 2008). This model of EI encompasses behavioral dispositions and selfperceived abilities of the individual. It is often measured using self-reported questionnaires, as opposed to the ability model that employs actual abilities. The trait model is required to be investigated within a personality framework (Kernbach and Schutte, 2005).

The mixed model presents EI as a framework of five skills and competences that enforce effective every day and leadership behavior (Goleman, 1998). These competences, which were developed by Goleman (1995) based on the framework of Salovey and Mayer (1989), are selfawareness, self-regulation, social skill, social awareness and self-motivation. Goleman (1995) views these competences as learned capabilities that can be improved over time and are therefore not innate talents, though he posits that individuals are born with a general EI that determines their potential for learning and building emotional competences.

Self-awareness is having sufficiently deep understanding of one's emotions, strengths, weaknesses, needs and drives (Goleman, 1998; Ozer et al., 2016). This understanding is fundamental to deciphering the psychological and emotional conditions of others. Of course, a person who cannot sufficiently understand his own emotions, strengths, weaknesses, needs and drives cannot understand those of others. Self-regulation is the capacity to adapt to changes and situations, including the ability to say no to impulsive urges (Goleman, 1995; Kernbach and Schutte, 2005). It is generally perceived as an EI skill relevant to coping with or managing the odds of other peoples' behaviors. In the health profession, such odds are commonplace.

The third skill, self-motivation, is the ability to dare to achieve, being passionate over profession and work and enjoying challenges and outcomes (Goleman, 1998; Bowen et al., 2016). Invariably it is the passion exercised in performing a task so that challenges and both positive and negative outcomes spurs the individual on to persist on the task as long as possible. A self-motivated health worker will therefore thrive on his or her job no matter the challenges faced. Social awareness is the ability to thoughtfully consider others' feelings when interacting or when relating with them (Goleman, 1995; Ozer et al., 2016). People with ample social awareness are not hasty in dissenting people's dispositions but rather take time to understand the basis of such dispositions and take empathetic actions in a manner that engenders happiness for themselves and those they interact with. The final ability of the mixed model is social skill, which is the ability to move people in a desired direction (Goleman, 1995; Freshman and Rubino, 2002). People with this ability are capable of influencing others to take decisions that harmonize with their desire and goal.

A major argument of Goleman's (1995) theory is that emotional intelligence is not an innate talent; rather, it is a malleable skill that can be developed over time, though everybody is born with some level of EI that facilitates the individual's social success and balance. This view suggests that an individual's EI level can improve with age. For health workers who have the opportunity to use their profession to exercise their EI, age and tenure may have a stronger effect on emotional intelligence advancement. The TWEE theory of Burdett and Coles (2010) lends support to this argument. TWEE theory originally posits that the wages of personnel, especially those making efforts to secure jobs that pay better, increase with their tenure and work experience. The theory thus suggests that tenure and work experience positively affect wage size. This relationship is driven by the fact that the employee's competences, which can include EI, improve over time.

The effects of tenure and education on EI have been confirmed in some studies (e.g., Lopes et al., 2006; Saddam-Hussain and Muhammad, 2010; Salehi et al., 2016), though none of them was focused on health workers; 
neither did any of them simultaneously test the individual and interaction effects of tenure, education and OJT, hereby referred to as demographics. Moreover, in a few instances, the effect of tenure and education on EI is negative, possibly due to research design issues such as failure to use sufficiently large samples, improper validation of the EI scale and failure to incorporate the covariance between the demographics in the models tested. In this study, the researchers attempt to address these issues in order to make more relevant recommendations for future research and to better identify implications for healthcare policy development and implementation.

Apart from the fact that most studies have confirmed a positive effect of tenure on EI, all identifiable studies (e.g., Lopes et al., 2006; Saddam-Hussain and Muhammad, 2010) have yielded findings that support the positive effect of age, which is related to tenure, on EI. The researchers therefore hypothesize that health workers' emotional intelligence is not significantly improved when they spend more years on the job (i.e., tenure does not make a significant positive effect on emotional intelligence of health workers). This hypothesis is labelled $\mathrm{H}_{1}$.

In Ghana and many other parts of the world, health professionals are exposed to various forms of career development programs. Typical among these programs are higher education and training or OJT programs, including seminars and conferences. Regardless of whether participation in these programs are driven by individual or organizational initiative, they can positively influence the ability of health workers to enhance competences such as EI. Moreover formal education is a process of training and development; hence it could be significantly correlated to OJT so that level of education changes with the level of access to training. The researchers therefore deem it important to test the following hypotheses, which are labelled $\mathrm{H}_{2}, \mathrm{H}_{3}$ and $\mathrm{H}_{4}$ :

$H_{2}$ : Health workers' emotional intelligence is not significantly improved when their level of formal education is increased (i.e., education makes no significant positive effect on EI development).

$H_{3}$ : Health workers' emotional intelligence does not significantly improve with increased level of training (i.e., OJT makes no significant positive effect on EI).

$H_{4}$ : There is no significant correlation between education and $O J T$

Health workers face various experiences on the job that provide opportunities for learning. Without learning on the job, either through experience or further education, a personnel may not be able to make the best of competences such as EI. Moreover, since formal education can accompany several forms of training, it can correlate with OJT when influencing EI. It can, as a result, be argued that education, tenure and OJT are significantly correlated. The researchers therefore pose and test two other hypotheses as follows:
$H_{4}$ : There is no significant correlation between education and tenure

$H_{6}$ : There is no significant correlation between OJT and tenure

On the basis of the last three hypotheses (i.e., $\mathrm{H}_{4}, \mathrm{H}_{5}$ and $\mathrm{H}_{6}$ ), the researchers expect to confirm significant correlations or covariance estimates for each pair of the three demographics. These three hypotheses are also limited to testing the correlation of each pair of the three demographics since for each pair a variable is a potential predictor of the other. In addition, the researchers do not have sufficient information to predict causation between each pair. Results of testing $\mathrm{H}_{4}, \mathrm{H}_{5}$ and $\mathrm{H}_{6}$ may nevertheless provide information about which variable predicts the other in each pair. Moreover, results of testing the six hypotheses should clearly guide future research on EI and healthcare policy relating to personnel's EI development. On the basis of this expectation, the researchers are poised to apply the most appropriate research methods and procedures to reach valid findings. The research methods adopted are presented in the next section.

\section{Materials and Methods}

Owing to resource constraints, the study was limited to Accra North. The population of research subjects therefore constituted health workers serving in healthcare institutions (i.e., clinics, polyclinics and hospitals) in the study area. The specific healthcare institutions used are those registered and controlled by Ghana Health Service (GHS). Health workers in institutions not controlled by GHS were not incorporated in the population because, in most cases, they are not formally trained based on GHS standards and are not officially recognized as health workers in Ghana. The study's accessible population was made up of health workers affiliated to all ten GHS-approved institutions in the study area. However some categories of personnel (i.e., security personnel, cleaners, gardeners and other administrative workers who did not make any influence on healthcare within the chosen institutions) were exempted. A total of 1,773 personnel made up the accessible population.

A sample of 1,047 personnel was drawn from the accessible population using simple random sampling, which is more suitable if research findings are to be generalized (Williams, 2007; Allwood, 2012). To enhance representativeness of the sample, each health institution was treated as a stratum from which a sample was drawn using the simple random sampling method. On the basis of applying the standard sample size determination table of Krejcie and Morgan (1970), the researchers ensured that the sample size drawn from each stratum was proportional to its population size. The sample size determination table of Krejcie and Morgan (1970) was used in view of the fact that its sample sizes 
were calculated using a relatively large population proportion of $5 \%$ and therefore provides access to the most representative sample. In sampling from each hospital, the researchers simulated numbers in MS Excel 2013 and assigned them to each healthcare personnel. Simulated numbers were exported to SPSS Version 21, where the random sampling function was activated and used to select participants. The overall sample of 1,047 was reached by adding sample sizes of the ten hospitals.

The 33-item measurement scale of Schutte et al. (1998) was adopted to measure EI through a self-reported questionnaire. Items of this scale were associated with five levels of response: Strongly disagree (1), disagree (2), not sure (3), agree (4) and strongly agree (5). "Not sure" was however assigned the numeric code 0 in data coding since it represents respondents' neutrality or uncertainty. Reliability of the measurement scale was assessed using the criteria $\mathrm{CA} / \mathrm{CR}>0.7, \mathrm{CR}>\mathrm{AVE}$ and AVE $>0.5$, which have been recommend by researchers (e.g., Hurley et al., 1997; Petrides and Furnham, 2000). Validity of the scale was examined using the criteria $\mathrm{MSV}<\mathrm{AVE}$ and $\mathrm{ASV}<\mathrm{AVE}$, which have also been recommended in the literature (e.g., Schutte et al., 1998; Hurley et al., 1997). Kindly refer to Table 1 for explanations to these criteria.

Reliability of the measurement scale was verified and confirmed to be appreciable. Evidences of data reliability are provided later in presenting results. Tenure was measured in terms of the number of years an individual had served on the job as a health worker. Education was measured in terms of the highest formal educational qualification of the health worker, whiles on-the-job training was measured in terms of the number of training programs (including seminars and conferences) the participant had participated in since he or she started working as a health professional.

Data was collected within twenty-eight (28) working days using hand delivery approach after management of participating healthcare institutions had endorsed the study. Each participant also formally agreed to participate by signing an informed consent form. The researchers collected data with the assistance of three hired persons. Within each healthcare institution, an administrative worker appointed by the head of administration guided and led questionnaire administration. Out of 1,047 questionnaires administered, 848 were returned by respondents. However 37 returned questionnaires had major response and nonresponse errors and were therefore discarded. Thus 811 questionnaires were analyzed. The researchers achieved a fairly balanced representation of individuals at each level of the predictors: Gender (males $=399$ and females $=412$ ); tenure (up to 2 years $=203,3-5$ years $=324$ and 6-10 years $=245$ ); education (diploma $=243$, degree $=364$ and Master's degree $=204)$; and ERT $($ One $=120$, Two $=122$, Four $=286$ and more than $5=283$ ).

In data analysis, descriptive statistics were used to identify potential outliers and to summarize the data. Exploratory Factor Analysis (EFA) was used for the purpose of reducing the dimension of the scale. Mean scores were computed for each item of the scale in estimating health workers' EI level. Results of the CFA showed that none of the $p 2$ values associated with the Mahalanobis distance test is less that 0.05 ; thus the smallest of the $p 2$ values is 0.132 . Data normality and the absence of outliers were therefore confirmed. To be able to test the hypotheses by imposing constraints on the structural model, gender was included as a fourth predictor of EI. The iterative CFA process also started with an over-identified model. AMOS was used to analyze data.

Table 2 shows extraction values of each of the items of EI. Based on the recommendation of Ringner (2008), all indicators are retained as measures of health workers' emotional intelligence for producing an extraction value of at least 0.5 . In addition, all items of the scale account for $88.32 \%$ of the total variation. The relatively large amount of the total variation accounted by the items buttresses the internal consistency of the scale. According to Tipping and Bishop (2007), a significant Bartlett's test of sphericity (at 5\% significance level) and a Keisser-Mayer-Olklin (KMO) value of at least 0.5 ought to be produced by a scale to meet sample size requirements. With reference to the bottom part of Table 3 , the measurement scale produces a KMO value of 0.922 and a significant Bartlett's test of sphericity at 5\% significance level.

Table 1 . Reliability and validity statistics

\begin{tabular}{|c|c|c|c|c|c|c|c|c|c|}
\hline \multirow[b]{3}{*}{ Construct } & \multirow[b]{3}{*}{$\mathrm{CA}$} & \multirow[b]{3}{*}{ CR } & \multicolumn{3}{|c|}{ ICC } & \multirow[b]{3}{*}{$\begin{array}{l}\text { P-value } \\
\text { (F-test) }\end{array}$} & \multirow[b]{3}{*}{ AVE } & \multirow[b]{3}{*}{ MSV } & \multirow[b]{3}{*}{ ASV } \\
\hline & & & \multirow[b]{2}{*}{$\begin{array}{l}\text { Single } \\
\text { measure }\end{array}$} & \multicolumn{2}{|c|}{ CI } & & & & \\
\hline & & & & $\begin{array}{l}\text { Lower } \\
\text { limit }\end{array}$ & $\begin{array}{l}\text { Upper } \\
\text { limited }\end{array}$ & & & & \\
\hline Self-awareness & 0.532 & 0.607 & 0.275 & 0.231 & 0.320 & 0.000 & 0.501 & 0.001 & 0.0002 \\
\hline Self-regulation & 0.453 & 0.528 & 0.293 & 0.229 & 0.355 & 0.000 & 0.488 & 0.137 & 0.0158 \\
\hline Social awareness & 0.225 & 0.260 & 0.127 & 0.058 & 0.194 & 0.000 & 0.167 & 0.165 & 0.0106 \\
\hline Self-motivation & 0.634 & 0.619 & 0.464 & 0.409 & 0.417 & 0.000 & 0.511 & 0.165 & 0.0230 \\
\hline Social skill & 0.403 & 0.478 & 0.252 & 0.187 & 0.318 & 0.000 & 0.321 & 0.137 & 0.0144 \\
\hline Overall (EI) & 0.776 & 0.751 & 0.240 & 0.217 & 0.265 & 0.000 & ------ & ------ & ------ \\
\hline
\end{tabular}

KEY: CA $=$ Chronbach's alpha; $\mathrm{CR}=$ Composite reliability; $\mathrm{ICC}=$ Intra-class correlations; $\mathrm{CI}=$ Confidence interval; $\mathrm{AVE}=$ Average Variance Estimate; MSV = Maximum Shared Squared Variance; AVS = Average Shared Squared Variance 
Table 2. Communalities

\begin{tabular}{ll}
\hline Variable & Extraction \\
\hline EI1 & 0.960 \\
EI2 & 0.937 \\
EI3 & 0.971 \\
EI4 & 0.757 \\
EI5 & 0.932 \\
EI6 & 0.894 \\
EI7 & 0.902 \\
EI8 & 0.949 \\
EI9 & 0.831 \\
EI10 & 0.852 \\
EI11 & 0.923 \\
EI12 & 0.886 \\
EI13 & 0.847 \\
EI14 & 0.865 \\
EI15 & 0.976 \\
EI16 & 0.926 \\
EI17 & 0.881 \\
EI18 & 0.870 \\
EI19 & 0.868 \\
EI20 & 0.850 \\
EI21 & 0.918 \\
EI22 & 0.868 \\
EI23 & 0.812 \\
EI24 & 0.808 \\
EI26 & 0.961 \\
EI27 & 0.891 \\
EI28 & 0.962 \\
EI30 & 0.860 \\
EI31 & 0.807 \\
EI33 & 0.938 \\
Note: & 0.662 \\
El0 & 0.906 \\
Iators & 0.873 \\
\hline
\end{tabular}

Note: 10 factors are retrieved, with a total variance of $88.32 \%$

Table 1 shows reliability and validity statistics associated with dimensions of the measurement scale. In this table, each dimension of EI has CA and CR values less than the baseline value of 0.7 recommended by researchers (e.g., Morse, 2002; Drost, 2011). However the entire EI scale satisfies this criterion. Based on Hurley et al. (1997), failure of each dimension of EI to satisfy the CA/CR $>0.7$ criterion is not an issue since the CFA model focuses on the whole EI scale and the ICC values and their corresponding $\mathrm{p}<0.5$ result represent acceptable reliability of each dimension. In Table 1, the AVE $>0.5$ and CR $>$ AVE criteria recommended by researchers (e.g., Hurley et al., 1997; Schutte et al., 1998) are achieved for some dimensions and the overall scale. Additionally, the scale has sufficient discriminant validity on the basis of each of its dimensions satisfying the $\mathrm{MSV}<\mathrm{AVE}$ and $\mathrm{ASV}<\mathrm{AVE}$ criteria recommended by researchers (e.g., Hurley et al., 1997; Petrides and Furnham, 2000). The reliability and validity of the entire EI scale is therefore confirmed.
Table 3. Descriptive statistics

\begin{tabular}{|c|c|c|c|}
\hline & Mean & Std. Deviation & Analysis N \\
\hline EI1 & 4.15 & 1.07 & 811 \\
\hline EI2 & 4.25 & 0.70 & 811 \\
\hline EI3 & 4.30 & 0.96 & 811 \\
\hline EI4 & 3.40 & 1.20 & 811 \\
\hline EI5 & 3.15 & 1.02 & 811 \\
\hline EI6 & 4.20 & 0.68 & 811 \\
\hline EI7 & 4.20 & 0.81 & 811 \\
\hline EI8 & 4.00 & 0.71 & 811 \\
\hline EI9 & 4.10 & 0.70 & 811 \\
\hline EI10 & 4.35 & 0.79 & 811 \\
\hline EI11 & 3.65 & 0.91 & 811 \\
\hline EI12 & 4.30 & 0.78 & 811 \\
\hline EI13 & 4.00 & 0.55 & 811 \\
\hline EI14 & 4.30 & 0.64 & 811 \\
\hline EI15 & 3.60 & 1.12 & 811 \\
\hline EI16 & 4.35 & 0.57 & 811 \\
\hline EI17 & 4.55 & 0.50 & 811 \\
\hline EI18 & 3.80 & 1.16 & 811 \\
\hline EI19 & 3.85 & 0.79 & 811 \\
\hline EI20 & 4.55 & 0.50 & 811 \\
\hline EI21 & 3.70 & 1.19 & 811 \\
\hline EI22 & 3.75 & 0.99 & 811 \\
\hline EI23 & 4.40 & 0.58 & 811 \\
\hline EI24 & 4.50 & 0.59 & 811 \\
\hline EI25 & 3.80 & 1.21 & 811 \\
\hline EI26 & 3.95 & 0.92 & 811 \\
\hline EI27 & 4.10 & 0.70 & 811 \\
\hline EI28 & 2.10 & 1.34 & 811 \\
\hline EI29 & 3.60 & 0.92 & 811 \\
\hline EI30 & 4.20 & 0.93 & 811 \\
\hline EI31 & 4.25 & 0.62 & 811 \\
\hline EI32 & 3.90 & 0.94 & 811 \\
\hline EI33 & 3.35 & 0.96 & 811 \\
\hline \multicolumn{2}{|c|}{ KMO } & 0.922 & \\
\hline \multicolumn{2}{|c|}{ Approx. Chi-Square } & 13603.6 & \\
\hline \multicolumn{2}{|c|}{ df } & 528 & \\
\hline \multicolumn{2}{|l|}{ Sig. } & 0.000 & \\
\hline
\end{tabular}

Table 3 shows descriptive statistics (i.e., mean scores and their associated standard deviations) of all items of the measurement scale. The mean scores express the extent to which a variable represents an aspect of health workers' emotional intelligence. A mean score closer to 5 , the maximum value of the measurement scale, indicates that the item is a facet of health workers' emotional intelligence; except for the negative counter items, which must have a mean score closer to 1 . In Table 2, all items produce a mean score close to 5 or above 3, except the negative item EI28. Since all negative items are expected to produce a mean score closer to 1, EI28 is an aspect of health workers' EI. Though the other two negative items (i.e., EI5 and EI33) have unexpectedly large mean scores, they are accepted as part of health workers' EI on the basis of the EFA results presented earlier. Results of data analysis and processing are presented in the next section. 


\section{Results}

Table 4 shows the correlation between EI and the demographics. From the table, EI is significantly negatively correlated to gender $(\mathrm{R}=-0.335 ; \mathrm{p}<0.05)$, whereas it is positively correlated to education $(\mathrm{R}=0.463, \mathrm{p}<0.05)$, tenure $(\mathrm{R}=0.212, \mathrm{p}<0.05)$ and training $(\mathrm{R}=0.583$, $\mathrm{p}<0.05)$. The negative correlation between EI and gender suggests that males and females have different EI levels.

Table 5 shows notes about the fitted model. It shows that a positive degree of freedom of 1 is produced and this outcome suggests that our fitted model is satisfactorily over-identified. This table also shows evidence relating to absolute model fit, which is represented by the small chi-square statistic and the $\mathrm{p}$ value that is greater than 0.05 (i.e., $\chi^{2}=2.382$; $p$-value $=$ $0.123)$. Table 6 shows the actual measures of absolute fit. Discrepancy in this table stands for the chi-square value $\left(\chi^{2}\right)$, the primary statistic of absolute fit. According to Petrides and Furnham (2000), its value is expected to be small and its p-value must be greater than the 0.05 cut-off value. Since these criteria are met, the researchers deem their model to be of good fit (i.e., $\chi^{2}=2.382$; $p$ value $=0.123$ ). Moreover, the fact that the independence model has a large chi-square value and a p-value less than $5 \%$ backs the fit of the default model (i.e., $\chi^{2}=$ 866.162; p-value $=0.000)$. According to Schutte et al. (1998), the Random Mean Square Error of Approximation (RMSEA) and Tucker-Lewis Index (TLI) values are theoretically required to be less than
0.06 and greater than 0.95 respectively for a well fitted model. In Table 5, these criteria are met.

Table 7 shows the regression weights and covariance estimates of the model. In this table each of the demographics significantly predicts health workers' emotional intelligence at 5\% significance level. Whiles gender and educational level make a negative effect on EI, the other demographics make a positive significant effect on EI. In view of the positive correlation between EL and EI in Table 4, the negative effect of EL at the CFA level might be as a result of the interaction effects of the other demographics on it. The negative correlation between gender and training and between gender and education suggest that males and females do not have the same level of education and training. In this situation, the relatively strong correlation between EL and training might have led to a negative effect of EL on EI.

In Table 7, all hypothesized covariances are confirmed at 5\% significance level. Gender and EL have one of the smallest covariance of -0.1 , whereas EL and training have the largest positive covariance of 0.6. In Table 8 , gender yields the largest negative direct and total effect on EI (i.e., $\beta_{\text {gender }}=-11$ ). This relatively large effect must have contributed to the negative effect of education on EI (i.e., $\beta_{\text {education }}=-5.08$ ). Training makes the largest positive total and direct effect on EI (i.e., $\beta_{\text {training }}=4.76$ ), followed by tenure (i.e., $\beta_{\text {tenure }}=0.89$ ). As reflected in Table 8 , none of the demographics makes a significant indirect effect on EI. Figure 1 is a framework of the results.

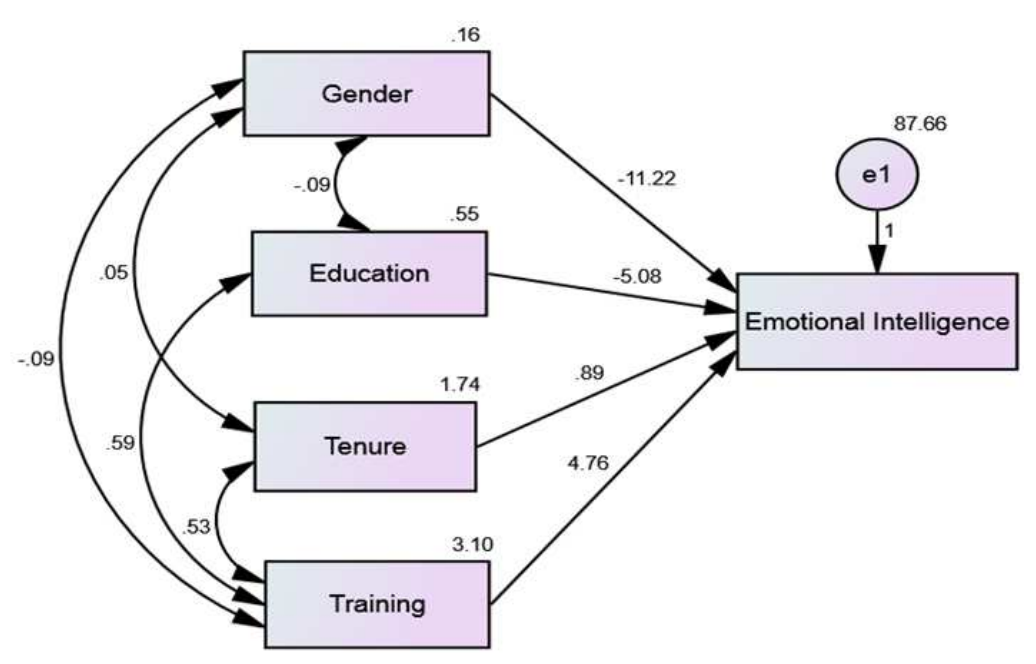

Fig. 1. The Resulting model

Table 4. Correlation matrix

\begin{tabular}{llllll}
\hline & Gender & Education & Tenure & Training & EI \\
\hline Gender & 1 & $-0.305^{* * *}$ & 0.072 & $-0.129^{* * *}$ & $-0.335^{* * *}$ \\
Education & & 1 & 0.054 & $0.463^{* * *}$ & $0.121^{* * *}$ \\
Tenure & & 1 & $0.249^{* * *}$ & $0.212^{* * *}$ \\
Training & & & 1 & $0.583^{* * *}$ \\
EI & & & & 1 \\
\hline
\end{tabular}

*** Correlation significant at $1 \%$ significance level (two-tailed) 
Table 5. Notes for fitted model

\begin{tabular}{lll}
\hline & Note & Value \\
\hline Notes for Model (Fitted) & Number of distinct sample moments & 15 \\
& Number of distinct parameters to be estimated & 14 \\
& DF & 1 \\
& Minimum was achieved & 2.382 \\
& Chi-square $\left(\chi^{2}\right)$ & 0.123 \\
\hline
\end{tabular}

Table 6. Fit measures

\begin{tabular}{|c|c|c|c|}
\hline & Measure & Default & Independence \\
\hline \multirow[t]{5}{*}{ Fit measures } & Discrepancy $\left(\chi^{2}\right)$ & 2.382 & 866.162 \\
\hline & $\mathrm{p}$-value & 0.123 & 0.000 \\
\hline & $\mathrm{DF}$ & 1.000 & 10.000 \\
\hline & TLI & 0.984 & 0.000 \\
\hline & RMSEA & 0.042 & 0.325 \\
\hline
\end{tabular}

KEY: DF = degree of freedom; TLI = Tucker-Lewis Index; RMSEA = Random Mean Square Error of Approximation

Table 7. Unstandardized regression estimates

\begin{tabular}{llllllrr}
\hline Estimates & DV & Path & IV & Estimate & S.E. & C.R. & p-value \\
\hline Weights & EI & $<---$ & Gender & -11.000 & 0.9 & -13.0 & 0.000 \\
& EI & $<---$ & EL & -5.100 & 0.5 & -9.7 & 0.000 \\
& EI & $<---$ & Tenure & 0.900 & 0.3 & 3.4 & 0.000 \\
Covariance & EI & $<---$ & Training & 4.800 & 0.2 & 22.0 & 0.000 \\
& Tenure & $<-->$ & Training & 0.500 & 0.1 & 7.0 & 0.000 \\
& EL & $<-->$ & Training & 0.600 & 0.0 & 12.0 & 0.000 \\
& Gender & $<-->$ & Training & -0.100 & 0.0 & -3.6 & 0.000 \\
& Gender & $<-->$ & EL & -0.100 & 0.0 & -8.4 & 0.000 \\
& Gender & $<-->$ & Tenure & 0.001 & 0.0 & 2.6 & 0.001 \\
\hline
\end{tabular}

KEY: DV = dependent variable; IV = independent variable; S.E. = standard error; C.R. = critical ratio; EI = emotional intelligence; $\mathrm{EL}=$ educational level

Table 8. Effects

\begin{tabular}{lllll}
\hline & Training & Tenure & EL & Gender \\
\hline Total effects & 4.76 & 0.89 & -5.08 & -11.2 \\
Direct effects & 4.76 & 0.89 & -5.08 & -11.2 \\
Indirect effects & 0.000 & 0.000 & 0.000 & 0.000 \\
\hline
\end{tabular}

\section{Discussion}

Results of the study show that each of the demographics make a significant effect on the emotional intelligence of health workers. Training makes the largest positive effect on emotional intelligence, followed by tenure. The positive effects of training and tenure in this vein suggests that health workers' emotional intelligence improves with increased level of access to OJT and the number of years spent on the job. The confirmed effect of tenure on EI confirms Goleman's (1995) EI theory, which asserts that individuals' emotional intelligence change over time. The confirmed effects of training is also supported by some studies (Lopes et al., 2006; Saddam-Hussain and Muhammad, 2010; Schutte et al., 2013). Moreover Schutte et al. (2013) theoretical argument that training is an activity that enables individuals to enhance their EI is supported.

Educational level makes a rather negative effect on EI, even though the EI-EL correlation is positively significant. Though some studies such as Lopes et al. (2006) produced a negative effect of education on EI, the majority of studies (e.g., Saddam-Hussain and Muhammad, 2010; Danquah and Wireko, 2014) yielded a positive effect. Moreover the TWEE theory and Goleman (1995) EI theory imply that skills such as emotional intelligence is enhanced as the level of education improves. With reference to Table 4, education shares the largest correlation coefficient with training and gender, whiles a very weak correlation exists between tenure and education. The researchers consequently reason that the negative effect of education on the EI of health workers is driven by the influence of training and gender. Moreover though training makes the strongest correlation with EI, it does not make the strongest effect on EI; rather gender makes the strongest effect on EI. This evidence suggests that training makes some of its influence on gender and education. Training must have also empowered tenure to make a significant effect on EI. Hence training is the primary predictor of EI. 
Like those of training and education, the confirmed negative effect of gender on EI in this study is consistent with several studies (e.g., Lopes et al., 2006; Danquah and Wireko, 2014), with some studies reaching a positive effect of gender on EI (Farooq and Ur Rehman, 2011). The fact is that both positive and negative effects of gender on EI represent a significant difference in the EI level of males and females, though no theoretical explanation has been related to this finding. Yet as mentioned earlier in the literature review, the issue of gender inequality is still significantly prevalent in African organizations today, a situation that might have led to males and females not having equal access to career development opportunities in the ten healthcare institutions from which this study's sample was drawn.

\section{Conclusion and Recommendation}

Health workers' emotional intelligence is influenced by education, training, tenure and gender. That is to say increased tenure and higher level of access to training improve health workers' emotional intelligence in Accra North. Education, however, makes a negative effect on EI as a result of the controlled influence of training and gender on it. With respect to estimates shown in Fig. 1 and correlation coefficients in Table 4, training accounts for, at least, part of the effect made by gender, education and tenure on the emotional intelligence. All hypotheses tested, except $\mathrm{H}_{4}$, are supported by the data. The result confirms that education, training and tenure (which is prolonged through career development programs) are alternative means for developing health workers' emotional intelligence.

It is also evident that OJT is the predictor of educational level and tenure. In practice, the role of OJT as a predictor of tenure and education makes sense from this point of view: With higher level of training, personnel can enhance their tenure and therefore be able to make educational achievements on the job. This perspective more strongly applies to health professionals who depend on income made from their jobs to fund higher education. These personnel are likely to be those who engage in more training and are consequently empowered to excel on the job to earn higher remuneration, part of which is used to acquire higher education. Training can also empower personnel to achieve strides on the job, which might encourage management to reward them by supporting their higher educational pursuits. Success made on the job, possibly as a result of regular engagement in OJT, can lead to longer tenure as well. Yet future research would have to test the causal effect of OJT on tenure and educational level to make these views conclusive.

Depending on the nature of an organization's human resource policies, education and OJT constitute career development programs and opportunities. Hence training, education and tenure enhancement programs are all career development opportunities within an organization. So improving health workers' education, competences and work experience is the main means, hereby called the composite approach, for developing their EI. Under normal circumstances, this approach would yield maximum result if its individual methods (i.e., education, training and tenure promotion) are simultaneously applied within the organization.

Health service managers, healthcare institutions and governments can use education as a tool for enhancing the EI of health workers directly or indirectly. The direct way is to develop and implement policies that specify significant financial support (e.g., through scholarship schemes) for intelligent workers who would want to pursue higher education. Healthcare institutions can also collaborate with universities to give special EI education to their employees. At the national level, a grander way to give EI-focused education to health workers is to incorporate relevant lessons or modules to the educational curriculum of health professionals. Health workers' EI can be indirectly improved through education by enforcing policies that provide opportunities for individual employees to pursue higher and special education. For instance, health workers pursuing higher or special EI education can be exempted from work (e.g., by reducing the working hours) and may be given flexible work conditions that support learning.

Healthcare institutions, in collaboration with government, are expected to adopt the culture of prolonging the tenure of health workers. Training and education basically promote employee tenure; yet a portfolio of pathways must be adopted by healthcare institutions and governments within the framework of the said tenure prolongation culture. So apart from education and in-service training, institutions must employ strategies that minimize employee turnover. In view of this suggestion, jobs must be well designed and assigned to the right individuals, whiles appropriate motivation schemes are used to facilitate the satisfaction and loyalty of health workers.

In view of the worsening global economic downturn, nevertheless, many organizations may wish to optimize resources in investing towards the development of health workers' EI. Preference for a cost optimizing approach, which ultimately involves investing in a single method of the composite approach, will therefore be required. On the basis of the effects reached in this study, OJT is the best individual method for developing health wormers' emotional intelligence in a cost optimizing situation. Fortunately, the use of OJT gives the organization the opportunity to expose health workers to EI-specific training programs. The exposure of personnel to EI-focused training may more efficiently develop the emotional intelligence of health professionals. 


\section{Acknowledgement}

The researchers acknowledge Panyan Bodong and his team members at Abirem Government Hospital for their assistance in data collection.

\section{Funding Information}

It is disclosed that funds expended in conducting this study was contributed by the researchers. Funds were not sourced from any individual or organization.

\section{Author Contributions}

Nestor Asiamah: Conceived the research idea, designed the study, led data collection and analyzed the data.

Henry Kofi Mensah: Reviewed the literature and developed the study's introduction.

Eric Fosu Oteng-Abayie: Discussed the results, reviewed the analysis conducted by Nestor Asiamah, concluded the study, and compiled the manuscript. Each researcher proofread the compiled manuscript.

\section{Conflict of Interests}

The researchers declare no conflicts of interest.

\section{Ethics}

This study was carried out by the researchers based on the approval of the various hospitals that participated in it. Moreover it has not been published in any peerreviewed journal or related platform.

\section{References}

Allwood, C.M., 2012. The distinction between qualitative and quantitative research methods is problematic. Qualitative Quantitative, 46: 1417-1429. DOI: $10.1007 / \mathrm{s} 11135-011-9455-8$

Bar-On, R., 1997. Development of the BarOn EQ-i: A measure of emotional and social intelligence. Proceedings of the 105th Annual Convention of the American Psychological Association in Chicago, (PAC' 97).

Bowen, P., A. Pilkington and R. Rose, 2016. The relationship between emotional intelligence and well-being in academic employees. Int. J. Social Sci. Stud., 4: 1-9. DOI: 10.11114/ijsss.v4i5.1487

Brackett, M.A., J.D. Mayer and R.M. Warner, 2004. Emotional intelligence and its relation to everyday behaviour. Personality Individual Differences, 36: 1387-1402. DOI: 10.1016/S0191-8869(03)00236-8

Burdett, K. and M. Coles, 2010. Tenure and experience effects on wages: A theory.
Danquah, E. and T.B. Wireko, 2014. The impact of each element of emotional intelligence on customer service delivery: A customer satisfaction perspective. Int. J. Sales Market. Manage. Res. Develop., 4: 9-20.

Drost, E.A., 2011. Validity and reliability in social science research. Educ. Res. Perspect., 38: 105-123.

Farooq, M.U. and K. Ur Rehman, 2011. Emotional intelligence and organizational productiviy: A conceptual study. World Applied Sci. J., 15: 821-825.

Freshman, B. and L. Rubino, 2002. Emotional intelligence: A core competency for health care administrators. Health Care Manager, 20: 1-9. DOI: 10.1097/00126450-200206000-00002

Goleman, D., 1998. Working with Emotional Intelligence. 1st Edn., Bantam Books, New York, ISBN-10: 0553378589, pp: 383

Goleman, D., 1995. Emotional Intelligence. 1st Edn., Bantam Books, New York, ISBN-10: 055309503X, pp: 352.

Hurley, A.E., T.A. Scandura, C.A. Schriesheim, M.T. Brannick and A. Seers et al., 1997. Exploratory and confirmatory factor analysis: Guidelines, issues and alternatives. J. Organ. Behavior, 18: 667-683. DOI: 10.1002/(SICI)1099-1379(199711)18:6<667::AIDJOB874>3.0.CO;2-T

Kalyoncu, Z., S. Guney, M. Arslan, S. Guney and E. Ayranci, 2012. Analysis of the Relationship between emotional intelligence and stress caused by the organisation: A study of nurses. Bus. Intelli. J., 5: 335-346. DOI: 10.13140/RG.2.1.4815.0883

Kaur, D., M. Sambasivan and N. Kumar, 2015. Significance of Spiritual (SI) and Emotional Intelligence (EI) on the caring behavior of nurses. J. Community Public Health Nurs., 1: 1-3. DOI: $10.4172 / 2471-9846.1000101$

Kernbach, S. and N.S. Schutte, 2005. The impact of service provider emotional intelligence on customer satisfaction. J. Service Market., 19: 12-19. DOI: $10.1108 / 08876040510625945$

Krejcie, R.V. and D.W. Morgan, 1970. Determining sample size for research activities. Educ. Psychol. Measure., 30: 607-610. DOI: $10.1177 / 001316447003000308$

Landy, F.J., 2005. Some historical and scientific issues related to research on emotional intelligence. J. Organ. Behavior, 26: 411-424. DOI: 10.1002/job.317

Locke, E.A., 2005. Why emotional intelligence is an invalid concept. J. Organ. Behavior, 26: 425-431. DOI: $10.1002 /$ job. 318

Lopes, P.N., D. Grewal, J. Kadis, M. Gall and P. Salovey, 2006. Evidence that emotional intelligence is related to job performance and affect and attitudes at work. Psicothema, 18: 132-138. PMID: 17295970 
Mayer, J.D. and P. Salovey and D.R. Caruso, 2004. Emotional intelligence: Theory, findings and implications. Psychological Inquiry, 15: 197-215. DOI: $10.1207 / \mathrm{s} 15327965$ pli1503 02

Mayer, J.D., 2008. Human abilities: Emotional intelligence. Ann. Rev. Psychol., 59: 507-536. DOI: 10.1146/annurev.psych.59.103006.093646

Morse, J.M., 2002. Verification strategies for establishing reliability and validity in research. J. Educ. Res., 6: 56-63.

Nwankwo, B.E., T.C. Obi, N. Sydney-Agbor, S.A. Agu and J.U. Aboh, 2013. Relationship between emotional intelligence and job satisfaction among health workers. IOSR J. Nurs. Health Sci., 2: 19-23.

Opuni, F.F., E. Opoku and M. Oseku-Afful, 2014. The effect of relationship marketing on service quality and customer satisfaction in the hospitality sector in Ghana: The moderating role of service providers' emotional intelligence. Brit. J. Market. Stud., 2: 1-16.

Ozer, O., E. Hamarta and M.E. Deniz, 2016. Emotional intelligence, core-self evaluation and life satisfaction. Psychology, 7: 145-153. DOI: $10.4236 /$ psych.2016.72017

Petrides, K.V. and A. Furnham, 2000. On the dimensional structure of emotional intelligence. Personality Individual Differences, 29: 313-320. DOI: $10.1016 / \mathrm{S} 0191-8869(99) 00195-6$

Ringner, M., 2008. What is principal component analysis? Nature Biotechnol., 26: 303-304. DOI: $10.1038 /$ nbt0308-303
Saddam-Hussain, R. and I. Muhammad, 2010. Emotional intelligence and organizational Performance: (A case study of banking sector in Pakistan). Int. J. Bus. Manage., 5: 191-197. DOI: 10.5539/ijbm.v5n10p191

Salehi, M., M.A. Zadeh, A. Ghaderi and A.Z. Tabasi, 2016. A study of the effect of education and academic environment on emotional intelligence on accounting students in Iran. Int. Educ. Stud., 9: 182-188. DOI: 10.5539/ies.v9n1p182

Salovey, P. and J.D. Mayer, 1989. Emotional intelligence. Imaginat. Cognit. Personality, 9: 185-211. DOI: 10.2190/DUGG-P24E-52WK-6CDG

Schutte, S.N., J.M. Malouff, L.E. Hall, D.J. Haggerty and J.T. Cooper et al., 1998. Development and validation of a measure of emotional intelligence. Personality Individual Differences, 25: 167-177. DOI: 10.1016/S0191-8869(98)00001-4

Schutte, N.S., J.M. Malouff and E.B. Thorsteinsson, 2013. Increasing emotional intelligence through training: Current status and future directions. Int. J. Emotional Educ., 5: 56-72.

Tipping, M.E. and M.B. Bishop, 2007. Probabilistic principal component analysis. J. Royal Stat. Society, Series B, 61: 611-622. DOI: 10.1111/1467-9868.00196

Tyczkowski, B., C. Vandenhouten, J. Reilly and S.M. Kubsch, 2015. Emotional Intelligence (EI) and Nursing leadership styles among nurse managers. Nurs. Administrat., 39: 172-180.

DOI: 10.1097/NAQ.0000000000000094

Williams, C., 2007. Research methods. J. Bus. Econom. Res., 5: 65-72. 